$09 ; 15$

\title{
Компактная лазерная система для дистанционных измерений методом лазерно-искровой эмиссионной спектроскопии на основе Nd: YAG-лазера с самообращением волнового фронта
}

\author{
(С В.Ф. Лебедев ${ }^{1,2}$, К.В. Павлов ${ }^{1}$, Г.В. Бурковский ${ }^{3}$, А.В. Федин ${ }^{3}$ \\ ${ }^{1}$ Санкт-Петербургский национальный исследовательский университет информационных технологий, механики и оптики \\ (Университет ИТМО), Санкт-Петербург, Россия \\ ${ }^{2}$ Санкт-Петербургский государственный университет аэрокосмического приборостроения, \\ Санкт-Петербург, Россия \\ ${ }^{3}$ Владимирский государственный университет им. А.Г. и Н.Г. Столетовых, Владимир, Россия \\ E-mail: lebedev@oi.ifmo.ru
}

Поступило в Редакцию 24 декабря 2018г.

В окончательной редакции 24 декабря 2018г.

Принято к публикации 7 февраля 2019г.

Предложена компактная лазерная система на основе Nd:YAG-лазера с самообращением волнового фронта для дистанционного анализа веществ методом лазерно-искровой эмиссионной спектроскопии на расстоянии не менее $10 \mathrm{~m}$.

DOI: 10.21883/PJTF.2019.09.47705.17654

Лазерно-искровая эмиссионная спектроскопия (ЛИЭС) является одним из наиболее перспективных методов дистанционного химического анализа веществ в любом агрегатном состоянии. В лазерной системе для проведения измерений методом ЛИЭС (ЛИЭС-система) в качестве источника излучения обычно используется коммерческий лазер с ламповой накачкой и линейным резонатором [1,2]. В ряде работ продемонстрировано существенное увеличение интенсивности излучения плазмы исследуемого вещества и, как следствие, получение более интенсивного аналитического сигнала в виде линейчатого спектра излучения плазмы при использовании парных лазерных импульсов с подстраиваемой задержкой между ними $[3,4]$. Подобные ЛИЭС-системы наиболее часто создаются по двухканальной схеме с использованием двух отдельных лазеров, работающих в режиме активной модуляции добротности. Это существенно усложняет ЛИЭС-систему, приводит к увеличению ее массогабаритных параметров и делает более сложным применение метода в полевых условиях и в режиме реального времени. Для получения парных лазерных импульсов может быть успешно применен $\mathrm{Nd}$ :YAG-лазер, работающий в режиме пассивной модуляции добротности. В этом случае варьирование величин задержек между импульсами излучения не является произвольным, однако схема лазера упрощается из-за отсутствия высоковольтной электронной системы управления оптическим затвором.

В настоящей работе впервые предлагается ЛИЭС-система с высокими энергетическими и пространственными характеристиками лазерного излучения на основе малогабаритного импульсного Nd:YAG-лазера с самообращением волнового фронта при многоволновом взаимодействии в активной (усиливающей) среде и пассивном лазерном затворе (ПЛЗ).
Оптическая схема разработанного лазера включала один активный элемент (АЭ) на основе кристалла $\mathrm{Nd}$ :YAG размером $\varnothing 8 \times 180 \mathrm{~mm}$ с концентрацией ионов $\mathrm{Nd}^{3+}$ на уровне 0.9 at.\%, восемь отражающих зеркал и ПЛ3 на основе кристалла $\mathrm{LiF}: \mathrm{F}_{2}^{-}$с начальным пропусканием, варьирующимся в диапазоне $T_{0}=14-17 \%$. Поперечная накачка АЭ осуществлялась шестнадцатью импульсными матрицами лазерных диодов типа СЛМ 3-2 с максимальной суммарной энергией излучения $E_{\text {pump }}=14.5 \mathrm{~J}$ и частотой следования импульсов до $10 \mathrm{~Hz}$. Матрицы лазерных диодов располагались вдоль АЭ в четыре ряда (по четыре матрицы в каждом ряду). Габаритный размер резонатора вдоль оси распространения выходного луча лазера составил $0.6 \mathrm{~m}$ [5].

Лазерная генерация начинается с возникающего в АЭ шумового излучения и формирования с помощью системы отражающих зеркал внутрирезонаторных пучков, пересекающихся в АЭ и ПЛЗ (рис. 1). В процессе развития генерации усиливающиеся внутрирезонаторные пучки записывают в АЭ и ПЛЗ динамические пропускающие решетки коэффициента усиления и показателя преломления соответственно, формируя динамически самоподстраивающийся резонатор лазера. На образовавшихся решетках происходит перераспределение поля излучения в резонаторе и обращение его волнового фронта. Динамические решетки производят селекцию пространственных, спектральных и поляризационных характеристик излучения, а ПЛЗ позволяет получить одномодовое излучение в виде цуга импульсов наносекундной длительности.

Энергетические параметры лазерной генерации измерялись с помощью пироэлектрического приемника Ophir PE50BF-DIV-V2, а временны́е - с помощью лавинного фотодиода Ophir FPS1 SENSOR ROHS и двухлучевого осциллографа LeCroy WaveJet 352A (500 MHz). С увели- 


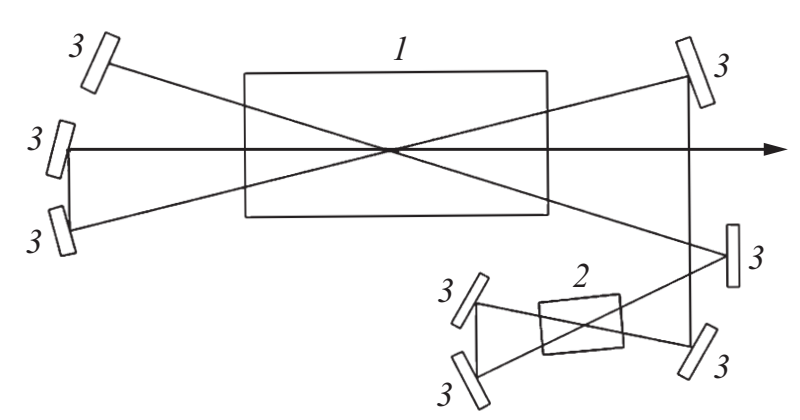

Рис. 1. Схема импульсного Nd:YAG-лазера с самообращением волнового фронта. 1 - активный элемент, 2 - пассивный затвор (кристалл $\mathrm{LiF}: \mathrm{F}_{2}^{-}$), 3 - отражающие зеркала.

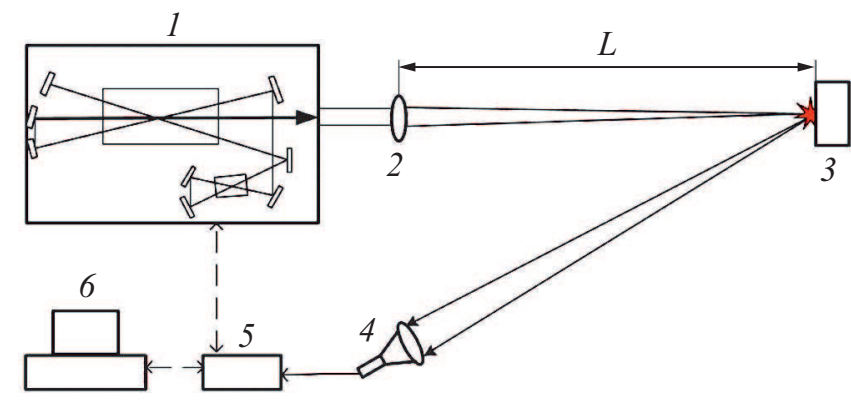

Рис. 2. Лазерная система для измерений методом ЛИЭС. 1 - Nd:YAG-лазер с самообращением волнового фронта, 2 - фокусирующая система, 3 - исследуемый образец, 4 система приема излучения, 5 - спектрометр, 6 - компьютер. $L-$ расстояние до мишени.

чением энергии импульсов накачки с 7.7 до $14.5 \mathrm{~J}$ увеличивалось число импульсов в цуге с 1 до 11 и сокращался период их следования со 100 до $30 \mu \mathrm{s}$, причем энергия и длительность отдельного лазерного импульса в цуге оставались неизменными величинами: $230 \mathrm{~mJ}$ и $11 \mathrm{~ns}$ соответственно. Измеренное методом ножа Фуко в двух ортогональных направлениях значение параметра качества пучка не превышало $M^{2} \leqslant 1.2$. Качество лазерного пучка контролировалось также с помощью CCD-камеры BeamGage SP620U (Ophir-Spiricon).

Схема ЛИЭС-системы приведена на рис. 2. Оптическая система фокусировки излучения включала расширитель пучка с переменным увеличением 10ВЕ03-2-12 (Standa) и длиннофокусную линзу с апертурами $50 \mathrm{~mm}$. Излучение плазмы собиралось оптической системой, состоящей из фокусирующей линзы 4 с апертурой $50 \mathrm{~mm}$ и коллимационной линзы COL-UV/VIS (Avantes), соединенной со спектрометром 5. Излучение передавалось по оптоволокну диаметром $600 \mu \mathrm{m}$ на входную апертуру спектрометра AvaSpec-ULS2048L-USB2 (Avantes) co спектральным разрешением $1 \mathrm{~nm}$. Запуск лазера, синхронизация его работы со спектрометром, регистрация и обработка спектров плазмы осуществлялись с помощью собственного программного обеспечения [6].
Использованный в предлагаемой ЛИЭС-системе лазер может переходить в режим генерации коротких импульсов с помощью внешнего плазменного зеркала, образованного лазерной плазмой исследуемого материала. В этом случае формируется цуг коротких лазерных импульсов, но с достаточно нестабильными энергетическими и временны́ми параметрами; однако и в таком режиме генерации автоматическая идентификация материалов методом ЛИЭС была успешно продемонстрирована [7].

Важно отметить, что эффективность работы ЛИЭС-системы в этом случае также обеспечивалась соответствующим алгоритмом обработки спектров излучения плазмы, устойчивым к изменению интенсивности излучения плазмы от импульса к импульсу [6]. Важной математической процедурой современных алгоритмов обработки спектров излучения плазмы является их нормализация, т.е. вычисление относительного вклада полосы излучения исследуемого химического элемента в полный спектр излучения плазмы. При этом надежность работы алгоритма выше, если процедура нормализации применяется к спектру плазмы, полученному после каждого лазерного импульса, а не к осредненному по серии импульсов. Это подтвердилось в процессе автоматического распознавания материалов в широком диапазоне изменений интенсивности излучения плазмы (до 100 раз) вследствие варьирования временны́х задержек открытия спектрометра относительно лазерного импульса [8]. Алгоритм был успешно применен и в режиме реального времени в задаче качественного определения коэффициента распределения лития между кристаллом и расплавом на примере лазерного кристалла форстерита $\mathrm{Li}, \mathrm{Cr}-\mathrm{Mg}_{2} \mathrm{SiO}_{4}$ [6].

Измерения с помощью предложенной ЛИЭС-системы проводились при двух различных режимах работы лазера: пассивной модуляции добротности в режиме генерации одиночного импульса или цуга из двух импульсов, а также самомодуляции добротности на внеш-

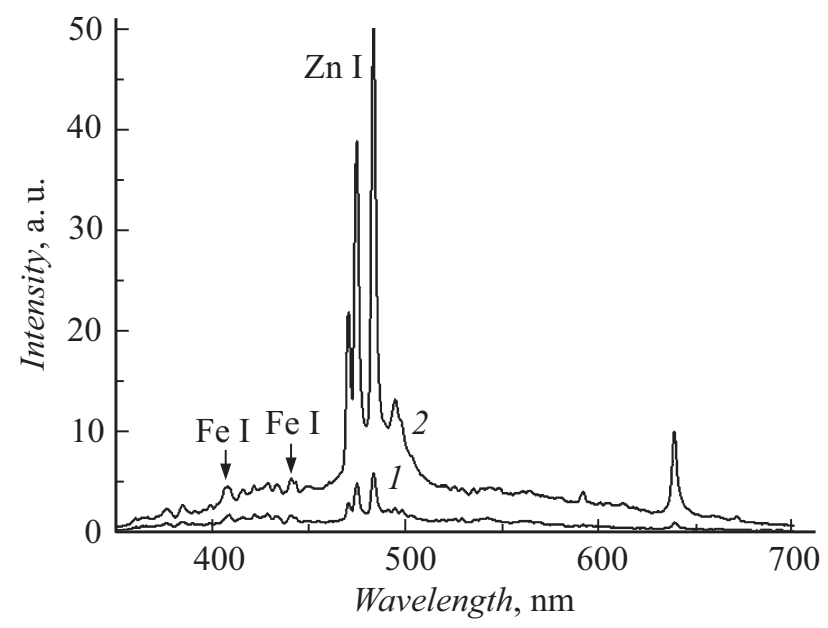

Рис. 3. ЛИЭС-спектр при двухимпульсном воздействии на образец оцинкованной стали. $L=5 \mathrm{~m}$. 1 - один импульс, 2 - два импульса. 
нем плазменном зеркале. Была продемонстрирована возможность автоматического распознавания материалов на расстояниях до $10 \mathrm{~m}$ (наибольшее возможное расстояние в наших лабораторных условиях). Алгоритм автоматической идентификации материала мишеней и тип материала мишеней (сталь, цинк, алюминий, бетон и т.д.) были аналогичны приведенным в работе [8]. В результате предварительных экспериментов регистрировались характерные ЛИЭС-спектры интересующих материалов и составлялась соответствующая база данных. Применявшаяся ранее процедура обработки спектров [8] была дополнена рядом процедур, необходимых для компенсации фонового излучения, увеличения отношения сигнал/шум, выделения полос излучения и их идентификации, увеличения спектрального разрешения и т.д. [6].

В экспериментах по автоматической идентификации веществ использовался двухимпульсный режим работы лазера, причем в этом случае наблюдался не менее чем шестикратный рост аналитического сигнала. В частности, при суммарной энергии двух лазерных импульсов $50 \mathrm{~mJ}$ амплитуда аналитического сигнала на расстоянии $5 \mathrm{~m}$ до мишени уже достигала величины насыщения приемника излучения (рис. 3). Период следования импульсов, определяемый начальным пропусканием ПЛЗ, подбирался в интервале от 30 до $100 \mu \mathrm{s}$ и в итоге устанавливался равным не более $30 \mu \mathrm{s}$. Уменьшение числа импульсов в цуге обеспечивалось уменьшением длительности импульса тока накачки. Возможное объяснение физического механизма увеличения аналитического сигнала при подобном двухимпульсном лазерном воздействии на исследуемый материал приведено в работе [9].

Анализ результатов измерений интенсивности ЛИЭС-сигнала в зависимости от расстояния при двухимпульсном лазерном воздействии на мишень позволил получить оценку предельного расстояния $(L=12.5 \mathrm{~m})$ для измерений с помощью предложенной ЛИЭС-системы. Следует отметить, что эта величина далека от реальных возможностей системы, поскольку апертура приемного телескопа составляла всего $50 \mathrm{~mm}$ (рис. 2).

Таким образом, использование импульсного $\mathrm{Nd}$ :YAG-лазера с самообращением волнового фронта обеспечивает возможность создания простой, компактной и, как следствие, надежной системы для дистанционной диагностики материалов методом лазерно-искровой эмиссионной спектроскопии, в том числе и в режиме реального времени.

\section{Список литературы}

[1] Yang C.S.-C., Jin F., Trivedi S.B., Brown E.E., Hommerich U., Tripathi A., Samuels A.C. // Appl. Spectroscopy. 2017. V. 71. N 4. P. 1-7.

[2] Son J.-G., Li Y., Ko D.-K. // Appl. Phys. Express. 2018. V. 11. N 10. P. 102401 (1-5).
[3] Laser-induced breakdown spectroscopy: theory and applications / Eds S. Musazzi, U. Perini. N.Y.: Springer, 2014. $565 \mathrm{p}$.

[4] Sun D., Su M., Dong C., Wen G. // Plasma Sci. Technol. 2014. V. 16. N 4. P. 374-379.

[5] Бурковский Г.В., Федин А.В., Погода А.П., Борейшо А.С. // Квантовая электроника. 2016. Т. 46. № 11. С. 976-978.

[6] Lebedev V.F., Makarchuk P.S., Stepanov D.N. // Spectrochim. Acta B. 2017. V. 137. P. 23-27.

[7] Лебедев В.Ф. // Опт. журн. 2017. Т. 84. В. 2. С. 19-27.

[8] Lebedev V.F., Shestakov A.A. // Proc. of SPIE. 2011. V. 7822. P. $78220 \mathrm{~V}(1-6)$.

[9] Першин С.М. // Квантовая электроника. 1989. Т. 16. № 12. C. $2518-2520$ 